Sharif University of Technology
Scientia Iranica
SCIENTIA
IRAN ICAA

\title{
On the assessment of a new steel bolted flush end-plate beam splice connection
}

\author{
H. Keikha and M. Mofid* \\ Department of Civil Engineering, Sharif University of Technology, Tehran, Iran.
}

Received 7 March 2015; received in revised form 29 December 2015; accepted 30 May 2016

\section{KEYWORDS}

Bolted flush end-plate connection;

Beam splice;

Finite element;

Pre-fabrication;

Performance

investigation;

Analytical model;

Parametric regression analysis.

\begin{abstract}
This paper describes the development of a numerical model with the ability to simulate and analyze the mechanical behavior of different types of Double Bolted Flush End-plate Beam (DBFEB) splice connections, which thus far has not been reported. Moreover, Bolted Flush End-plate Beam (BFEB) splice connections have been investigated for calibration of the results using Finite Element Modeling (FEM). The initial stiffness, rotation capacity, strength ratio, ductility, failure mode, and the performance of these two types of connections have been investigated and compared with each other with respect to FEMA 356. Also, classification of these two types of connections is performed by Eurocode 3 recommendation. The analyses have been calibrated and converted to experimental and analytical results, which are also briefly reviewed in this paper. Also, due to the multitude of influencing parameters, an analytical description of the behavior of DBFEB connections has been delivered based on component method. Moreover, several parametric analyses on the Initial Rotational Stiffness $\left(S_{\mathrm{ini}}\right)$ of DBFEB connection have been conducted using regression analysis of FEM results.
\end{abstract}

(C) 2017 Sharif University of Technology. All rights reserved.

\section{Introduction}

The study and use of end-plates in moment resisting frames for beam-to-beam splices and beam-to-column connections date back to the early 1960's. In the United States, these connections were primarily used in pre-engineered metal buildings until the mid-1980's; but, because of better seismic performance of new developed seismic connections, extensive use of endplate connections is limited. The pre-engineered metal building industry, which primarily uses built up steel sections for light one-story buildings, found these connections to be very economical for several reasons. The shop welding required for the end-plates was feasible due to the welding that was already required for the

*. Corresponding author.

E-mail addresses: keikha@alum.sharif.edu (H. Keikha); mofid@sharif.edu (M. Mofid) built up members. Also, the plate material used for the end-plates could be cut from the same plate from which the flanges of the built up sections were cut. Further, erection of the metal buildings was relatively simple due to all bolted connections, thus being advantageous. No field welding was required, allowing construction to be done in cold conditions and construction time to be reduced. Eventually, because of more accurate fabrication and better design techniques, the use of moment end-plates has become more economically feasible for use in multi-story buildings. Also, as a result of poor performance of flange-welded moment connections in comparison to the performance of bolted and riveted moment connections in the 1994 Northridge earthquake and the 1995 Kobe earthquake, end-plate moment connections have been under serious consideration as an alternative to welding in seismic regions.

Hot rolled beams and plate girders can have 


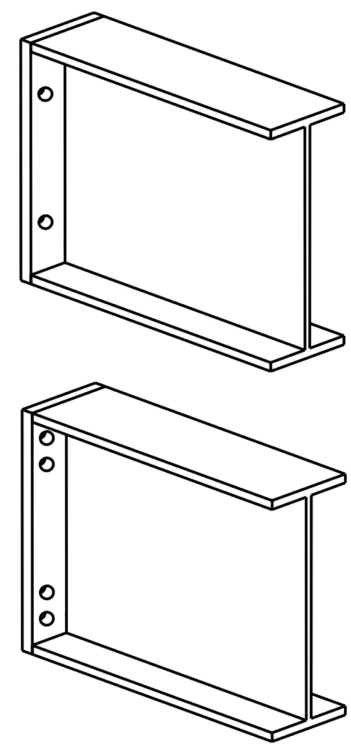

(a) Unstiffened

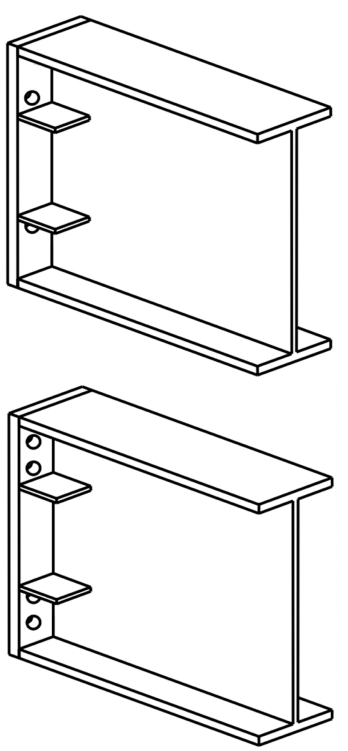

(b) Stiffened
Figure 1. Typical configurations for flush end-plate connections.

splices along their length due to construction or design requirements. These requirements can be referenced as: 1) smaller beam length than span length, 2) shipping limitations, and 3) camber prevention, and 4) design cross-section change [1]. End-plate moment connections consist of a plate that is shop-welded to the end of a beam that is then field bolted to the connecting member using rows of high-strength bolts. The connections are primarily used either to connect a beam to a column or to splice two beams together. There are two major types of end-plate connections: flush and extended. A flush end-plate connection has an end-plate that does not extend beyond outside of the connecting beam flanges and all of the bolt rows are positioned inside the flanges. Flush end-plate connections can be stiffened or unstiffened. The stiffened configurations have gusset plates (stiffeners) welded to the beam web and to the end-plate on both sides of the web. The stiffeners can be positioned between the bolt rows or outside the bolt rows. The typical uses of flush end-plate connections are illustrated in Figure 1.

Bolted end-plate connections are further described by the number of bolts at the tension flange and the configuration of the bolt rows. For gravity and/or wind load applications, the endplate connection is often designed to carry tension only at one flange. For seismic/cyclic loading, where the connection may experience load reversals, the end-plate is designed to carry tension at both flanges. In steel frame analysis, conventional methods of analysis idealize the connections simplistically in two representations: rigid or pinned. However, the actual behavior of frame connections lies between these two extremes, which is semi-rigid [2], where considerable attention has been directed in recent years towards modeling of the response of semi-rigid connections. The socalled component method adopted by the Eurocode 3 [3] can quantify the behavior of semi-rigid connections. Moreover, it claims to be able to establish a predictable degree of interaction between the members based on the moment-rotation $(M-\theta)$ characteristics of the connection. In the study of these types of connections, the most relevant properties of connections are initial rotational stiffness, rotation capacity, strength ratio, and ductility. This paper uses a materially nonlinear 3D Finite Element Analyses (FEA) in order to investigate two kinds of bolted end-plate connections, which are: Bolted Flush End-plate Beam (BFEB) splice connections and Double Bolted Flush End-plate Beam (DBFEB) splice connections, where modeling of the second kind, namely DBFEB, thus far has not been reported. Configuration of these two kinds of connections is illustrated in Figure 2 [4]. The BFEB and DBFEB splice connections technically represent, in principle, an extremely complex and highly indeterminate analytical problem with a wide range of geometrical and mechanical parameters affecting its moment-rotation behavior. These parameters are comprised of beam flange and web thicknesses, beam depth, flush end-plate thickness and width, bolt size, grade, length, and configuration.

Many tests on end-plate connections have been reported over the years. However, connection types and details are numerous as well as innovative with many parameters that must be accounted for collectively to characterize the behavior. Moreover, such parameters do consider whether the end plate is flush or extended, whether the end plate extends beyond one or both sides of the beam flanges, and, if so, how much the length of this extension is. This continues with the diameter of the bolt, the number of bolt rows, the vertical and horizontal spacing of the bolts, the grade of the bolts, and the end-plate thickness; then, continued by stiffening of the end plate, the bolt pretension force, the dimensions of the beam and column, the yield strength of the steel, the coefficient of friction at the contact surface, etc. Therefore, it is almost impossible to study the behavior of these connections comprehensively, except through conducting physical tests. Furthermore, such testing can be costly where finite element modeling in lieu of physical modeling is an attractive option for developing a database of connection characteristics. Accurate modeling of connection elements as well as realistic simulation of the different material and geometric nonlinearities of connection characteristics is required in order to achieve acceptable results. There are several factors affecting the accuracy of FEM, including the mesh size and optimization of model meshing, material behavior of bolts, plate and profiles, choice of elements 


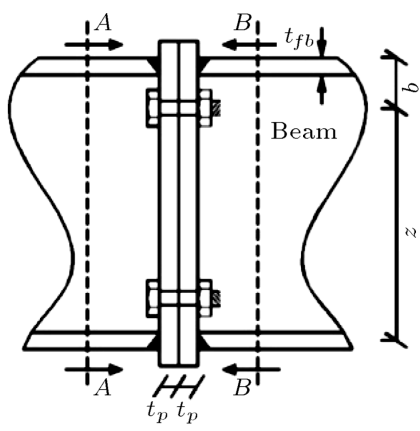

(a) DBFEB connection

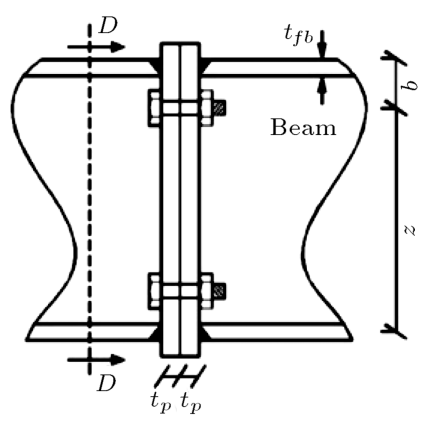

(d) BFEB connection

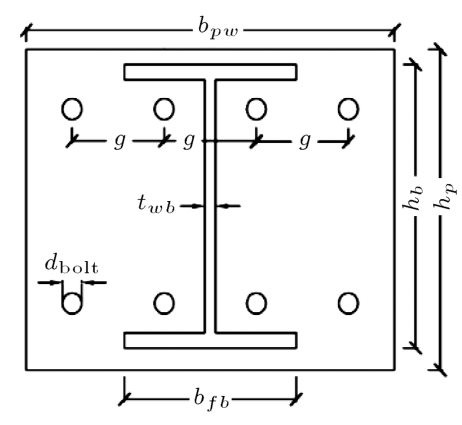

(b) Section A-A

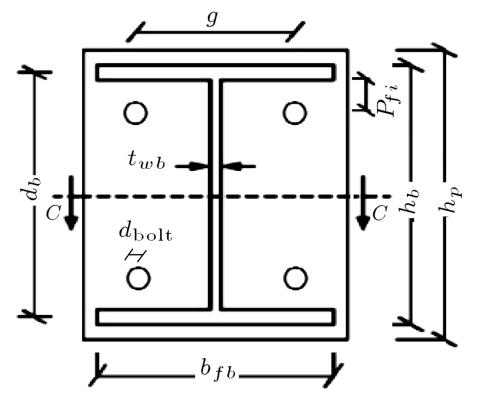

(e) Section D-D

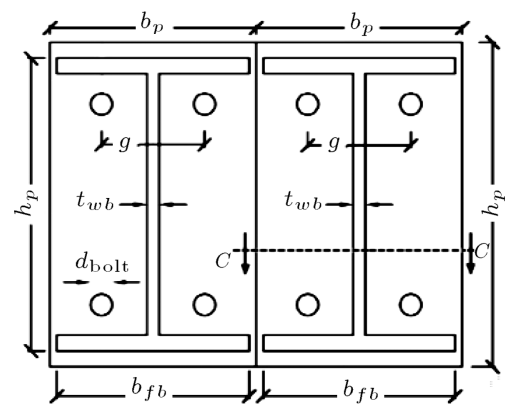

(c) Section B-B

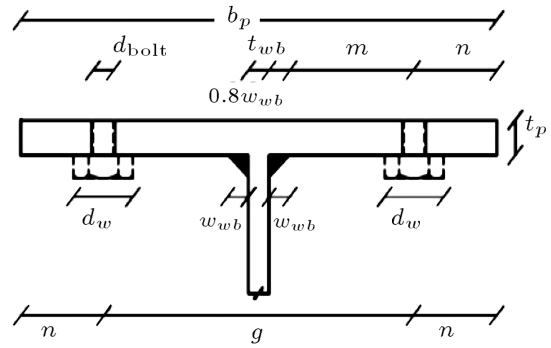

(f) Section C-C

Figure 2. The configurations of DBFEB and BFEB splice connections [4].

and, most importantly, the modeling of the contact behavior between elements and modeling of pretension bolts. The objectives of this investigation were:

1. To perform an accurate FEM in order to study the moment-rotation behavior of DBFEB and BFEB connections, which have the potential of extensive use in high-rise buildings and industrial structures;

2. To conduct a series of FEM along with an appropriate working procedure to determine initial stiffness, rotation capacity, strength ratio, ductility, and the performance of these types of connections;

3. To perform an analytical approach based upon component method to obtain the initial stiffness of DBFEB connection type by modeling the connection with a series of springs;

4. To express innovative parametric functions based upon combining component method and FEM results for investigating connection behavior;

5. To verify the presented parametric function by applying it to some cases and comparing the results with finite element models as well as analytical results.

\section{Flush end plate moment connections' state of the art}

Application of the flush end-plate found extensive use in the United States and the United Kingdom. The available research shows that extended end-plate connections with stiffeners perform better than flush end-plates in frames and have the added advantage of resisting lateral loads. Nevertheless, flush endplates have been used in a number of structures where geometry does not allow the use of extended endplates, such as roof connections of metal buildings as well as where lateral loads are minimal [4]. Phillips and Parker [5] studied the effect of the thickness of the end plate on flush end plate connections through experimental testing. There were two rows of bolts in the tension region in order to study the influence of the second row of bolts on the stiffness of the connections. They concluded that flush end-plates with two rows of bolts in the tension region were suitable for semi-rigid constructions, explaining that the second row of tension bolts was effective to an extent compared to what had been underestimated before. Zoetemeijer [6] proposed a chart for approximating the ultimate load capacity of a stiffened column flange or flush-end-plate when the distances of the bolt from the flange and web of the beam were known. Srouji et al. [7], after a review of earlier work of Douty and McGuire [8], Zoetemeijer [6], and Kennedy et al. [9] developed a methodology for the design of four configurations of end-plate connections consisting of two-bolt flush, four-bolt flush, unstiffened four-bolt extended, and stiffened four-bolt extended. He used the yield line method to determine end plate thickness along with a modification of the Kennedy's 
method to predict the bolt forces considering prying effects. Experimental testing results of these various configurations also were in good agreement with analytical methodology results for both the end-plate strength and bolt force magnitude. Hendrick [10] extended the work of Srouji and presented a unified yield-line based design procedure for four types of flush end-plate configuration. $\mathrm{Li}$ et al. [11] developed a method for the prediction of the moment capacities of flush end-plate composite connections. Merely as much as the tension side of the connection had to work in conjunction with reinforced concrete, much of their findings were applicable to this research. They reported possible failure modes based on careful study of various experimental data, including yield or fracture of bolts in tension, yield of the column flange in bending, weld failure between the end-plate and steel beam, yield or buckling of the lower beam flange in compression and shear, and yielding or buckling of the column web in transverse compression. Li et al. [11] also investigated the effect of the slab reinforcement on the flush end plate connection and derived equations for predicting moment capacity of such connections. At the same time, they proposed equations based on the number of bolts in both the tension and compression zones. It was also noted that the effect of the composite section on the connection could be treated as a row of bolts, where it would produce satisfactory results. Bursi and Jaspart [12] studied the behavior of the plastic and failure mechanism of a tee stub connection, which was later extended to investigate the behavior of end plate connections. They used brick as well as contact elements and based their conclusions on results from the finite element model. Bose et al. [13] developed a sophisticated three-dimensional model to investigate the behavior of unstiffened flush end-plate steel bolted joints using LUSAS commercial code. They compared the results with experimented data. The results confirmed the absolute accuracy of their finite element method prediction model. Olsen [14] proposed design formulae for bolted flush and extended end plates based on plasticity theory, where his model equation did not consider the effect of prying forces for flush end plates. The design formula was written in a generalized set for both flush and extended end plate connections. Murray and Shoemaker [15] presented a guide for the design of both extended and flush end-plate moment connections. Flush end-plate connections that could be designed were limited to four types. These four types were four-bolt unstiffened, two-bolt unstiffened, four-bolt stiffened with stiffeners between the tension flanges, and four-bolt stiffened with stiffeners inside the bolt rows. The provisions in the design guide are limited to gravity and low lateral loads. A unified design based on the Borgsmiller [16] method was used.

\section{Finite element analysis}

\subsection{Finite element model}

This paper simulates and analyzes DBFEB and BFEB connections having various types and details using FEM. Thus far, DBFEB joint types have not been modeled numerically or tested experimentally. The connections are all typical of those in multistory steel frames. In implementing the FEA, as there is a complex interaction between bolted connection components, a 3D nonlinear FEM connection model for the DBFEB and BFEB connections of the types was previously generated and shown in Figure 2 [4]. The technique of FEA lies in the development of a suitable mesh arrangement. Therefore, at the beginning of the research, a number of different trial models were created. On the account of the fact that the mesh configuration must balance the need for a fine mesh to give an accurate stress distribution and reasonable analysis time, the optimal solution is using a fine mesh in areas of high stress along with a coarser mesh in the remaining areas. In the 3D modeling herein, all elements of the beams, end-plates, and the highstrength bolts were meshed by the 8-node tetrahedral solid structural elements. Each node has 3 degrees of freedom. This kind of elements can tolerate irregular shapes without immense loss of accuracy. Figure 3 shows a typical finite element model of a DBFEB connection, and that of a high-strength bolt is shown in Figure 4 . The complex interactions among the surfaces of the flush end plates were considered as the surfaceto-surface contact, which would allow the finite sliding interaction between a deformable body and a rigid one. In detail, a Coulomb coefficient of friction equal to 0.3 is defined for sliding resistance. In the earlier finite element studies of bolted connections, such as those by Abolmaali et al. [17], Feng et al. [18], and Al-Jabri et al. [19], pretension effects in the bolts caused by

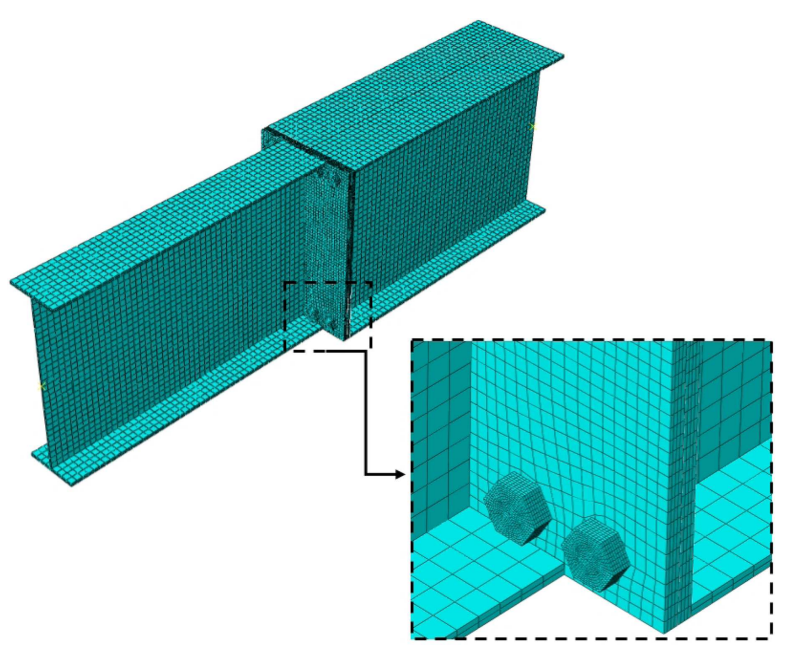

Figure 3. Typical finite element model of a DBFEB connection. 


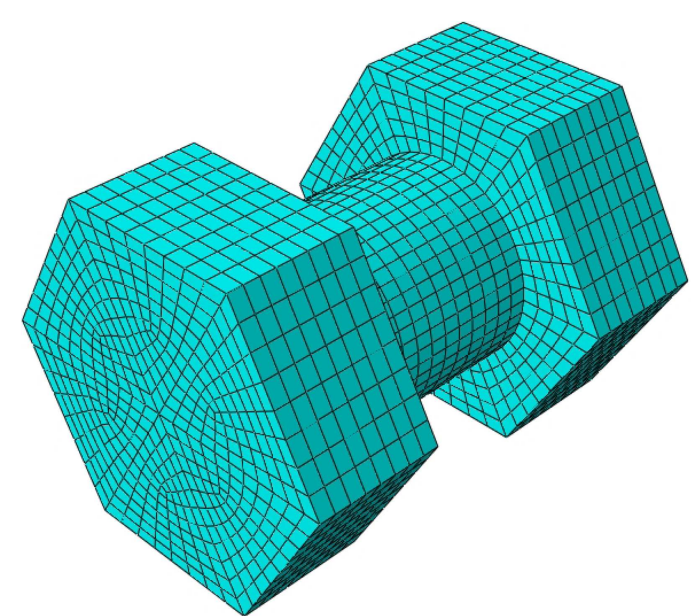

Figure 4. Finite-element model of high-strength bolt.

the tightening of each bolt were simulated through using the bolt pretension element, where it acted as a connecting element to connect the two imaginary parts of the bolt shank.

\subsection{Analysis methodology}

The accomplishment of the analysis and solution to the finite element modeling involved two load steps. First, the pretension forces were applied to the bolts. After solving the first load step, the second load step consisted of a downward displacement load being applied at the loading point identified on the beam in Figure 5. For facility and post-processing ease, the external load on the end of the beam web plate was applied in a displacement-driven manner. Therefore, loading was via a concentrated point load on the cantilever beam end. To prevent local yielding, rigid solid elements were used at the end of the beam. The iteration procedure was based on full Newton-Raphson iteration method, an iterative process of solving the nonlinear equations performed within each increment to achieve a quadratic convergence.

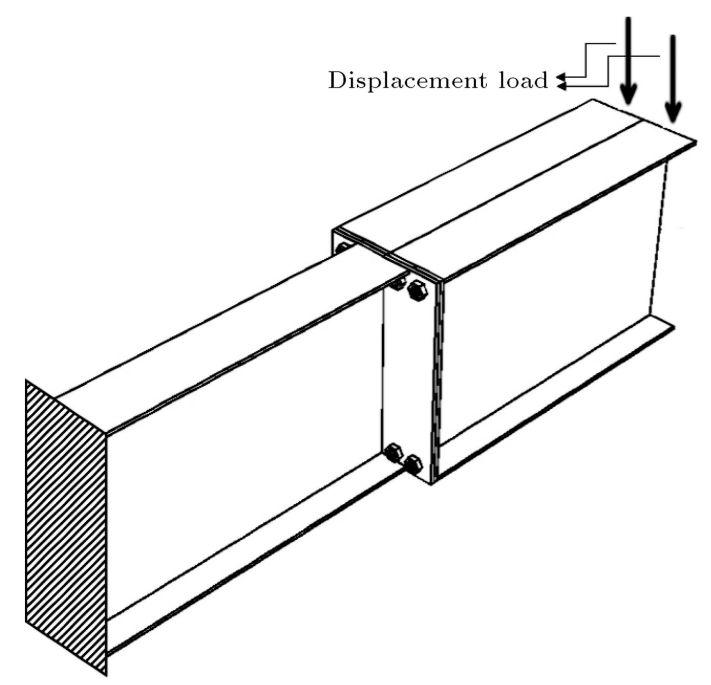

Figure 5. Typical connection prototype model.

\subsection{Material properties}

The stress-strain relationship for the elements of the end-plate and beam is taken as elastic-strain hardening for S235, which is defined by the means of a quadrilinear relationship as illustrated in Figure 6(a). For the elastic part of the stress-strain curve, the values of Young's modulus and Poisson's ratio of the steel are determined according to BS 5950 [17]; the values are $206 \mathrm{GPa}$ and 0.3 , respectively. The tangential stiffness beyond the yield point for beam and endplate steel is defined as $2 \%$ of the initial modulus of elasticity up to $11 \varepsilon_{y}$ followed by its related ultimate stress at $120 \varepsilon_{y}$ (see Figure 6(a)). For the bolt material, including shank and head, the second line connects the proof stress of the bolt to the yield stress that is considered to occur at a strain of $\varepsilon_{p}=3 \varepsilon_{y}$. The third line connects the second line to the ultimate stress presumed at an ultimate strain of $\varepsilon_{u}=8 \varepsilon_{y}$ [20] (see Figure 6(b)); finally, flat line up to the strain $\varepsilon_{u 2}=1.05 \varepsilon_{u}$ is considered (see Figure 6(a)). In the FEA, the coupled von-Mises yield criteria were used to obtain the response of the modeling in the inelastic region for the beam, end-plate, and bolt materials. Large displacement and large strain features are also used in the analysis in order to sufficiently simulate behavior of the connection components in ultimate states that are expected for this type of connection with grate geometrical nonlinearity, and also to consider the P-delta effect.

\section{Initial rotational stiffness}

The initial rotational stiffness $\left(S_{\text {ini }}\right)$ of the connections is determined from the initial slope of the momentrotation curves.

\subsection{Methods to predict DBFEB and BFEB initial stiffness \\ 4.1.1. Abolmaali prediction equation for initial stiffness of BFEB connection}

Abolmaali et al. [17] performed a parametric regression

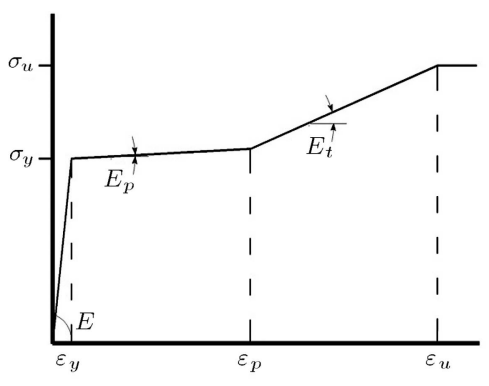

(a)

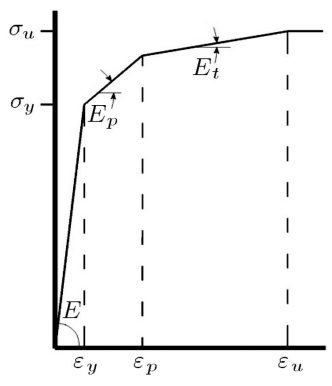

(b)
Figure 6. Idealized material behavior used in the FEM analysis: (a) End plates and beams and (b) high-strength bolts. 
study using 3D FEM modeling of the flush end-plate connection to develop the moment-rotation function for the flush end-plate type of connection. Based upon their recommended function, the initial stiffness of the flush end-plate type of connection is obtained as follows:

$$
\begin{aligned}
S_{\mathrm{ini}}= & g^{-0.558} \times d_{\mathrm{bolt}}^{0.899} \times\left(P_{f i}+t_{f b}\right)^{-2.490} \times b_{p}^{0.638} \\
& \times t_{p}^{0.658} \times t_{f b}^{0.197} \times t_{w b}^{0.619} \times \sigma_{y}^{0.358} \\
& \times \operatorname{EXP}(-0.75),
\end{aligned}
$$

where $S_{\text {ini }}$ is the initial stiffness in N.m/Rad, $\sigma_{y}$ is the beam yield stress in MPa, and the others are the connection's configuration parameters in mm, which are generally defined in Figure 2 .

\subsubsection{Mohamadi-Shooreh and Mofid prediction equation for initial stiffness of BFEB connection}

Mohamadi-Shooreh and Mofid [21] performed a parametric study using 3D modeling of the flush end-plate connection through inelastic FEA to obtain the initial rotational stiffness function for the flush end-plate type of connection. They suggested three different equations to predict $\mathrm{BFEB}$ initial stiffness as follows:

$$
\begin{aligned}
S_{\mathrm{ini}-\mathrm{eq} 1}= & \frac{E z^{2}}{\frac{m^{3}}{0.9 l_{\mathrm{eff}} t_{p}^{3}}+\frac{L_{\mathrm{bolt}}}{1.6 A_{s}}} \times d_{b}^{-0.135} \times b^{-0.744} \\
& \times m^{0.202} \times b_{p}^{0.501} \times t_{p}^{-0.045} \times t_{f b}^{0.214} \times t_{w b}^{0.150} \\
& \times d_{\mathrm{bolt}}^{-0.143} \times \operatorname{EXP}(0.6209)
\end{aligned}
$$

$$
S_{\text {ini-eq2 }}=\frac{1}{\frac{1}{k_{\text {eq-endplate }}}+\frac{1}{k_{\text {eq-bolt }}}},
$$

where $k_{\text {eq-bolt }}$ and $k_{\text {eq-endplate }}$ are obtained by the following equations:

$$
\begin{aligned}
k_{\text {eq-bolt }}= & \frac{E z^{2} L_{b}}{A_{s}} \times d_{b}^{0.181} \times b^{-1.029} \times m^{-0.757} \\
& \times b_{p}^{0.582} \times t_{p}^{1.077} \times t_{f b}^{0.279} \times t_{w b}^{0.076} \times d_{\mathrm{bolt}}^{-0.409} \\
\times & \operatorname{EXP}(2.648), \\
k_{\text {eq-endplate }}= & \frac{E z^{2} m^{2}}{t_{p}^{3}} \times d_{b}^{-0.142} \times b^{-0.727} \times m^{1.179} \\
& \times b_{p}^{0.340} \times t_{p}^{-1.709} \times t_{f b}^{0.256} \times t_{w b}^{0.174} \\
& \times d_{\mathrm{bolt}}^{0.629} \times \operatorname{EXP}(0.443) .
\end{aligned}
$$

To improve Eq. (3), they obtained the following equation:

$$
S_{\text {ini-eq3 }}=\frac{0.0473 \times \frac{b}{d_{\text {bolt }}}-0.291 \times\left(\frac{b}{d_{\text {bolt }}}\right)^{2}+1.429}{\frac{1}{k_{\text {eq-endplate }}}+\frac{1}{k_{\text {eq- bolt }}}},
$$

where $E$ is steel modulus of elasticity in $\mathrm{MPa}$ and $A_{s}$ is the tensile stress area of the bolt in $\mathrm{mm}^{2}$. All size parameters are in $\mathrm{mm}$, which are generally defined in Figure 2.

\subsubsection{Eurocode-3 suggestion equation for initial stiffness of DBFEB and BFEB connections}

For the bolted end-plate connections, Eurocode 3 [3] proposes that the rotation of the connection can be defined by attributing the deformation of the connection's components in tension zone, compression zone and shear zone. Based on the recommendation handed out in Eurocode 3 [3], for DBFEB and BFEB connections, the tension zone deformation comes from the deformation of end plate and bolt elongation. Besides, the end plate and each bolt row in the tension zone are simplified as a series of equivalent springs in which the initial rotational stiffness $S_{\text {ini }}$ is modeled analytically by a series of springs in tension zone of connection, possibly obtained from:

$$
S_{\mathrm{ini}}=\frac{E z^{2}}{\sum_{i} \frac{1}{k_{i}}}
$$

where $z$ is the lever arm generally defined in Figure 2 and $k_{i}$ is the stiffness coefficient for the basic joint component $i$, which for DBFEB and BFEB connections with single bolt row in tension is limited to $k_{5}$ and $k_{10}$. Stiffness coefficient for end plate in bending with single bolt row in tension, $k_{5}$, is expressed as:

$$
k_{5}=\frac{0.9 l_{\mathrm{eff}} t_{p}^{3}}{m^{3}}
$$

where $l_{\text {eff }}$ is the effective length and $m$ is generally defined as in Figure 2, which is equal to $g / 2-t_{w b} / 2-$ $0.8 w_{w b}$. The effective lengths for the bolt row below the beam tension flange are determined by the following values:

$$
l_{\mathrm{eff}}=\min (\alpha m, 2 \pi m),
$$

where $\alpha$ is a specified parameter in Figure 6.11 in part 1.8 of Eurocode 3 [3] and its value is between 4.45 and $2 \pi$. Thus, with the values of bolt distance from beam web, beam tension flange, and end-plate edge, the value of $\alpha$ is determined. Stiffness coefficient, $k_{10}$, for bolts in tension with single bolt row in tension below the beam flange, is expressed as:

$$
k_{10}=\frac{1.6 A_{s}}{L_{\mathrm{bolt}}},
$$




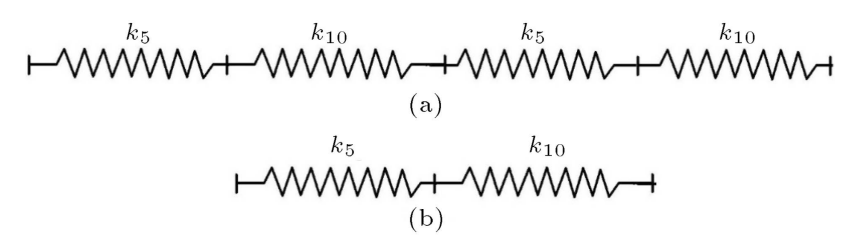

Figure 7. (a) Analytical models by a series of springs for evaluating initial stiffness of DBFEB. (b) BFEB connections.

where $A_{s}$ is the tensile stress area of the bolt and $L_{\text {bolt }}$ is the bolt elongation length, taken equal to the grip length (total thickness of material and washers) plus half the sum of the height of the bolt head and the height of the nut. Finally, the initial rotational stiffness of DBFEB and BFEB connections is computed by the following equations, respectively:

$$
\begin{gathered}
S_{\text {ini-EC3-DBFEB }}=\frac{E . z^{2}}{\frac{1}{k_{5}}+\frac{1}{k_{5}}+\frac{1}{k_{10}}+\frac{1}{k_{10}}} \\
=\frac{E . z^{2}}{2 \times\left(\frac{m^{3}}{0.9 L_{\text {eff }} \cdot t_{p}^{3}}\right)+2 \times\left(\frac{L_{\text {bolt }}}{1.6 A_{s}}\right)}, \\
S_{\text {ini-EC3-BFEB }}=\frac{E . z^{2}}{\frac{1}{k_{5}}+\frac{1}{k_{10}}}=\frac{E \cdot z^{2}}{\frac{m^{3}}{0.9 L_{\text {eff }} t_{p}^{3}}+\frac{L_{\text {bolt }}}{1.6 A_{s}}} .
\end{gathered}
$$

It is noteworthy that there has been no analytical model for evaluation of initial stiffness of DBFEB connection hitherto and it is conducted for the first time in this study. Figure 7 illustrates the created models for these two types of connections by a series of springs.

\section{Validation of the 3D FEM}

In order to assess the validity of the delivered 3D FEM, experimental and FEM studies performed by other researchers are used for direct verification. First, the experimental program revealed by Urbonas and Dainiunas [22], which was conducted on beam-to-beam flush end-plate connections, is used for comparison with the delivered 3D FEM results. Second, the presented 3D FEM results are compared with the experimental data generated by Broderick and Thomson [23], which was conducted on beam-to-column flush endplate connections. The column section that has been used is $203 \times 203 \times 86$ UC while two end-plates with different thickness sizes are engaged. Third, the six 3D FEM results presented by Abolmaali et al. [17] are also used for comparison. Finally, all of these previously mentioned samples that have also been performed and presented in 3D FEM by Mohamadi-Shooreh and Mofid [21] are used for comparison with the delivered 3D FEM results. Details of each specimen are given in Table 1.

The comparison of delivered 3D FEM, Eurocode 3 [3], Abolmaali et al. [17], and Mohamadi-Shooreh [21] for specimens No. 4 through 11 in terms of applied moment versus rotation is shown in Figure 8. In these diagrams, the rotation $\theta$ is the relative joint rotation of BFEB and DBFEB connections while $\theta_{L}$ and $\theta_{R}$ respectively illustrate the rotation of left and right components of the connection. Moreover, $\theta$ is equal to their difference in rotation as shown in Figure 9. Also, the joint moment is taken as the product of the load and its lever arm, which is the distance from the loading point to the center of end-plates, as shown in Figure 5. It is obvious that the numerical results have good agreement with the found results. Furthermore, to validate the accuracy of the delivered FEM in predicting the initial stiffness obtained from experimental results, various existing methods along with the delivered 3D FEM for DBFEB and BFEB

\begin{tabular}{|c|c|c|c|c|c|c|c|c|c|c|c|c|c|c|c|c|c|}
\hline \multirow[b]{2}{*}{ ID. no. } & \multicolumn{6}{|c|}{ Beam section } & \multicolumn{7}{|c|}{ End-plate configuration } & \multicolumn{3}{|c|}{ Bolt properties } & \multirow[b]{2}{*}{ Ref. } \\
\hline & $h_{b}$ & $b_{f b}$ & $t_{f b}$ & $t_{w b}$ & $\sigma_{y}$ & $\sigma_{u}$ & $h_{p}$ & $b_{p}$ & $t_{p}$ & $G$ & $b$ & $\sigma_{y}$ & $\sigma_{u}$ & $d_{\text {bolt }}$ & $\sigma_{y}$ bolt & $\sigma_{u \text { bolt }}$ & \\
\hline 1 & 320.0 & 160 & 11.5 & 7.5 & 235 & 370 & 320 & 180 & 20 & 100 & 54.25 & 235 & 370 & 24 & 640 & 800 & {$[22]$} \\
\hline 2 & 256.0 & 146.4 & 10.9 & 6.4 & 235 & 370 & 275 & 200 & 12 & 90 & 54.45 & 235 & 370 & 20 & 640 & 800 & {$[23]$} \\
\hline 3 & 256.0 & 146.4 & 10.9 & 6.4 & 235 & 370 & 275 & 200 & 20 & 90 & 54.45 & 235 & 370 & 16 & 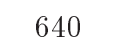 & 800 & [23] \\
\hline 4 & 609.6 & 127.0 & 9.50 & 4.8 & 248 & 350 & 609.6 & 127.0 & 12.7 & 69.9 & 39.7 & 248 & 350 & 19.05 & & & [17] \\
\hline 5 & & & & & & & & & & & & & & & & & {$[17]$} \\
\hline 6 & 609.6 & 177.8 & 9.50 & 4.8 & 248 & 350 & 609.6 & 177.8 & 12.7 & 69.9 & 23.8 & 248 & 350 & 19.05 & 55 & 11.7 & {$[17]$} \\
\hline 7 & 609.6 & 177.8 & 9.50 & 4.8 & 248 & 350 & 609.6 & 177.8 & 12.7 & 69.9 & 58.7 & 248 & 350 & 19.05 & 558.9 & .7 & {$[17]$} \\
\hline 8 & 609.6 & 177.8 & 9.50 & 2.5 & 248 & 350 & 609.6 & 177.8 & 12.7 & 69.9 & 39.7 & 248 & 350 & 19.05 & & & {$[17]$} \\
\hline 9 & 609.6 & 177.8 & 9.50 & 4.8 & 345 & 480 & 609.6 & 177.8 & 7.9 & 69.9 & 39.7 & 345 & 480 & 19.05 & 558.9 & 641.7 & {$[17]$} \\
\hline 10 & 304.8 & 127.0 & 8.50 & 4.0 & 249 & 380 & 304.8 & 127.0 & 12.7 & 76.2 & 27.5 & 249 & 38 & 15.88 & & & {$[17]$} \\
\hline 11 & 456.2 & 152.4 & 14.0 & 8.0 & 249 & 380 & 456.2 & 152.4 & 10.0 & 69.9 & 28.0 & 249 & 38 & 15.88 & 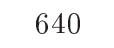 & 促 & {$[17]$} \\
\hline 12 & 660.4 & 152.4 & 15.0 & 10 & 249 & 380 & 660.4 & 152.4 & 12.7 & 82.6 & 35.0 & 249 & 380 & 19.05 & 640 & 800 & {$[17]$} \\
\hline
\end{tabular}
connection types, are summarized in Table 2. The

Table 1. Details of different test problems, beam, end plate, and bolts properties used for comparison.

Note: All dimensions are in $\mathrm{mm}$ and $\mathrm{MPa}$. 

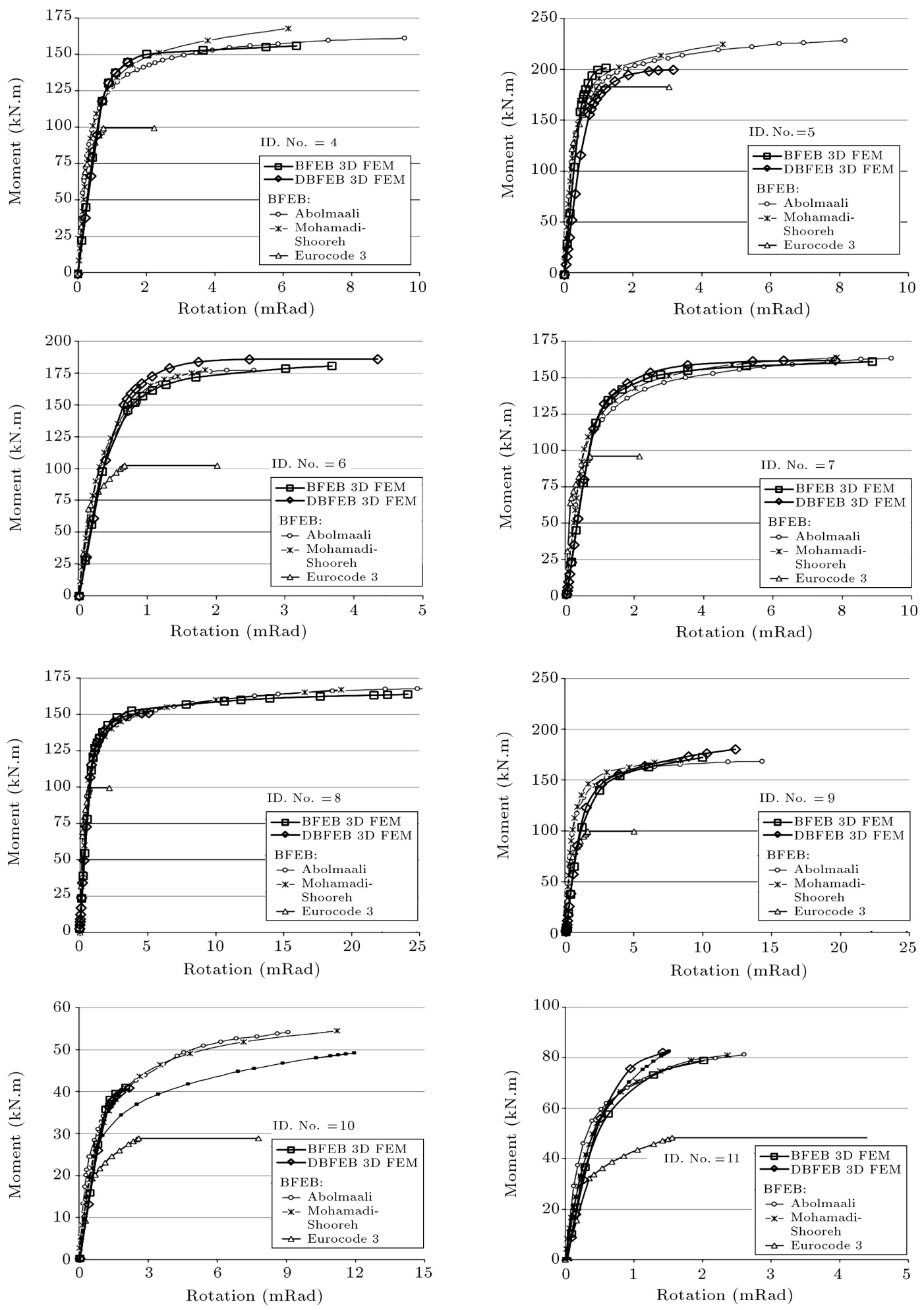

Figure 8. Comparison of the delivered 3D FEM and Eurocode 3 results with the results presented by Abolmaali et al.[17] and Mohamadi-Shooreh [21].

model can accurately simulate the initial stiffness of the moment-rotation curve, as in the simulation, where the fine mesh is used. In addition, the actual Young's modulus and Poisson's ratio of the used material are chosen. Regarding the plastic part of the curve, the modeling result is faintly higher. This is due to the plastic part of the steel stress-strain curve in the delivered 3D FEM model being considered as the idealized behavior of St-37 steel, which is different from those considered by Abolmaali et al. [17]. 
Table 2. Summary of the initial stiffness obtained by the experimental method, other existing methods, and 3D FEM.

\begin{tabular}{|c|c|c|c|c|c|c|c|}
\hline \multirow{3}{*}{ ID. no. } & \multicolumn{7}{|c|}{ Initial stiffness in various methods $(\mathrm{kN} . \mathrm{m} / \mathrm{mRad})$} \\
\hline & \multicolumn{5}{|c|}{ BFEB connection } & \multicolumn{2}{|c|}{ DBFEB connection } \\
\hline & $\begin{array}{l}\text { Experimental } \\
\text { results }\end{array}$ & $\begin{array}{c}\text { Eurocode } 3 \\
\text { suggestion } \\
\text { method }\end{array}$ & $\begin{array}{c}\text { Abolmaali } \\
\text { et al. }[17] \\
\text { parametric function }\end{array}$ & $\begin{array}{c}\text { Mohamadi-Shooreh } \\
{[21] \text { results }}\end{array}$ & $\begin{array}{c}\text { 3D FEM } \\
\text { results }\end{array}$ & $\begin{array}{c}\text { Eurocode } 3 \\
\text { suggestion } \\
\text { method }\end{array}$ & $\begin{array}{c}3 \mathrm{D} \text { FEM } \\
\text { results }\end{array}$ \\
\hline 1 & 79.48 & 99.8 & 63.59 & 83.18 & 81.53 & 59.572 & 56.21 \\
\hline 2 & 7.34 & 11.48 & 22.57 & 8.55 & 9.04 & 14.11 & 14.911 \\
\hline 3 & 3.81 & 10.92 & 25.84 & 5.23 & 5.17 & 16.861 & 22.433 \\
\hline 4 & 426.5 & 402.48 & 225.91 & 435.23 & 442.71 & 201.554 & 205.556 \\
\hline 5 & 586.82 & 536.49 & 362.65 & 618.49 & 593.43 & 259.59 & 221.903 \\
\hline 6 & 391.74 & 455.25 & 738.47 & 420.47 & 417.52 & 213.154 & 212.016 \\
\hline 7 & 202.59 & 401.74 & 123.97 & 225.35 & 230.47 & 188.119 & 131.606 \\
\hline 8 & 187.92 & 415.37 & 189.75 & 192.47 & 205.15 & 187.016 & 186.752 \\
\hline 9 & 208.43 & 177.78 & 231.17 & 217.64 & 209.56 & 83.584 & 96.999 \\
\hline 10 & 66.02 & 33.3 & 49.28 & 65.27 & 69.91 & 36.164 & 52.022 \\
\hline 11 & 243.01 & 92.85 & 164.11 & 233.19 & 250.36 & 81.509 & 81.049 \\
\hline 12 & 594.02 & 291.44 & 321.36 & 606.22 & 599.82 & 230.367 & 219.392 \\
\hline
\end{tabular}

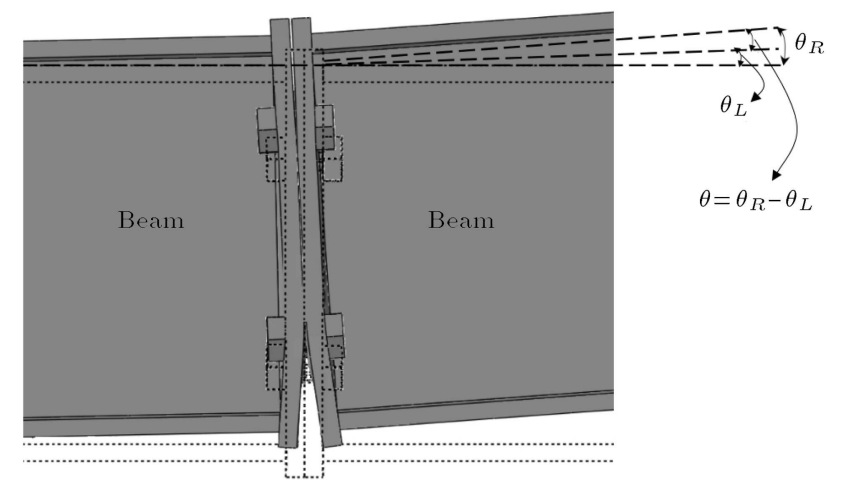

Figure 9. Schematic graph of joint rotation relationships.

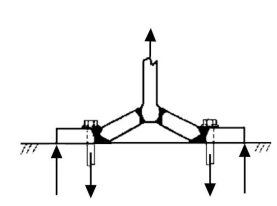

(a) Mode 1

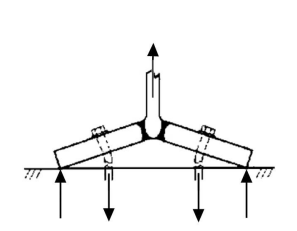

(b) Mode 2

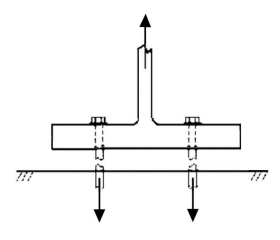

(c) Mode 3
Figure 10. Failure modes for a bolted end-plate connection.

\section{Monotonic characteristics of the DBFEB and BFEB connections}

\subsection{Failure modes}

The three main failure modes for a bolted end-plate connection considered by Eurocode 3 [3] are illustrated in Figure 10. These modes are defined as follows:
- Mode 1: Plastic hinges form at the bolt-line and at the beam web (Figure 10(a));

- Mode 2: Plastic hinges form at the beam web followed by yielding of the bolts (Figure 10(b));

- Mode 3: Yielding of the bolts only while the endplate remains elastic (Figure 10(c)).

These failure modes are defined by applying the yield line technique to an equivalent tee-stub section, including either the beam web and the end-plate or the column flange and web. Mode 1 joints can be expected to bear the highest ductility, but the lowest stiffness and moment resistance. In the opposite side, Mode 3 joints have the highest levels of moment resistance, but are subjected to a brittle failure mechanism. Mode 2 joints can resist in-between moments while remaining reasonably ductile.

\subsection{Rotation capacity}

The rotation capacity of the connections $\left(\theta_{u}\right)$ is determined as the maximum rotation before failure. FEMA356 [24] has classified the minimum plastic rotation of semi-rigid connections as an acceptance criterion with respect to their failure mode and their performance in "Immediate Occupancy (IO)," "Life Safety (LS)," and "Collapse Prevention (CP)" levels.

\subsection{Yield rotation}

The yield rotation of the connection is established based on the FEMA-356 recommendations [24]. In 


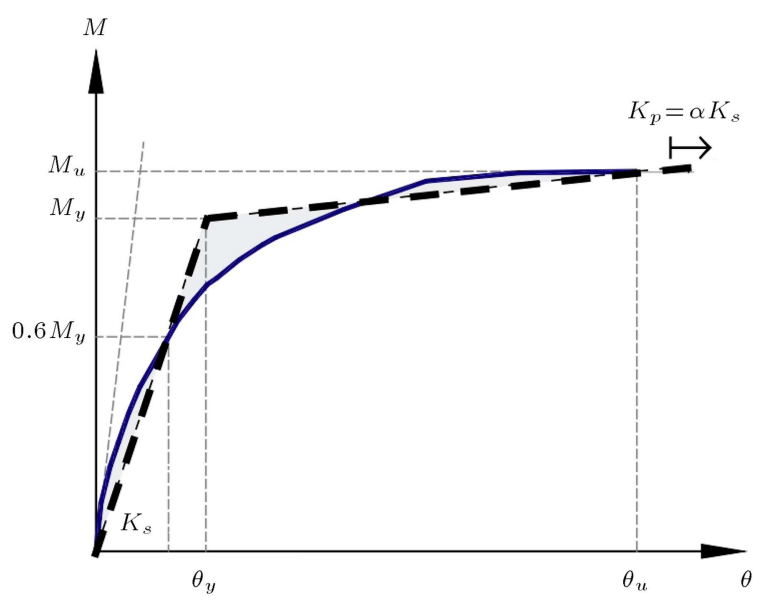

Figure 11. Definition of the yield point of the connection.

this method, the moment-rotation curve is defined by a bilinear curve with a post-yield slope $\left(K_{p}\right)$ as shown in Figure 11. The yield rotation $\left(\theta_{y}\right)$ is determined in the condition that the secant slope $\left(K_{s}\right)$ intersects the actual $M-\theta$ curve at $60 \%$ of the nominal yield moment $\left(M_{y}\right)$. At the same time, the area surrounded by the bilinear curve is equal to that surrounded by the original curve bounded by the peak rotation $\left(\theta_{u}\right)$.

\subsection{Evaluation of connection classification}

In order to determine the connection rigidity and strength in the moment-rotation curve for the DBFEB and BFEB connections under monotonic loading, the type of connection could be classified by Eurocode 3, Part 1-8 [3].

\subsubsection{Classification by rigidity}

A connection can be classified as rigid, nominally pinned, or semi-rigid according to its rotational stiffness by comparing its initial stiffness with classification boundaries suggested by Eurocode 3 [3].

- Rigid, if $S_{\text {ini }} \geq k_{b} E I_{b} / l_{b}$, where $k_{b}=8$ for non-sway frames, and $k_{b}=25$ for sway frames;

- Nominally pinned, if $S_{\text {ini }} \leq 0.5 E I_{b} / l_{b}$; otherwise, semi-rigid.

where $S_{\text {ini }}$ is the initial stiffness of connection, $E I_{b}$ is the flexural stiffness for the beam, and $l_{b}$ is the beam span.

\subsubsection{Classification by strength}

A connection can be classified as full-strength, nominally pinned, or of partial-strength in terms of strength by comparing its moment resistance with the plastic moment resistance of the beam:

- Full-strength, if $M_{u} \geq M_{b p}$;

- Nominally pinned, if $M_{u} \leq 0.25 M_{b p}$; otherwise, partial-strength,

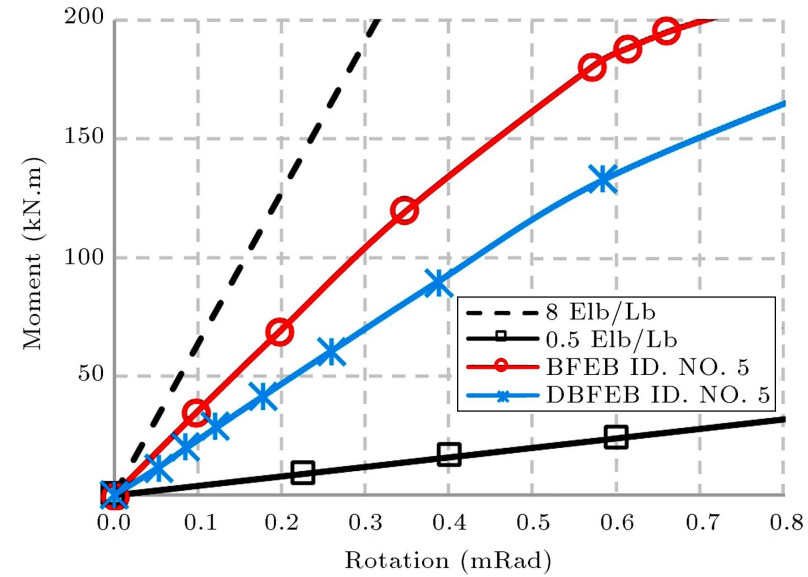

Figure 12. Classification of DBFEB and BFEB by rigidity.

where $M_{b p}$ is the design plastic moment resistance of the beam. According to the above classification method of connections, Figure 12, as an example, shows that DBFEB and BFEB connections presented herein could be classified as semi-rigid connections.

\section{Monotonic performance of the DBFEB and BFEB connections}

The monotonic performance of the DBFEB and BFEB connections with different material and geometric parameters is evaluated and discussed in this section. The assessment is based on the data obtained from specimens Nos. 1 through 12 with different types and details, which are described in Table 1.

\subsection{Key performance parameters}

7.1.1. Ductility

Ductility is defined as the ability of the structure to endure large plastic deformation without significant loss of strength [25]. The concept of ductility is a key element in earthquake-resistant design of structures. The assessment of ductility for connections can be carried out by calculating the ductility ratio $(\mu=$ $\left.\theta_{u} / \theta_{y}\right)$. Moreover, the ductility indicates the capability of the connection to accept nonlinear rotations without extensive damage.

\subsubsection{Strength ratio}

Strength (or resistance) ratio is an important parameter to evaluate the performance of connections. Strength deterioration is evaluated using the strength ratio, $\alpha_{r i}$, which is the ratio of the moment at peak rotation to the initial yield moment $\left(\alpha_{r i}=M_{u} / M_{y}\right)$.

\subsection{Performance evaluation of the DBFEB and BFEB connections}

The efficiency of the DBFEB and BFEB connections under monotonic loading is investigated by evaluating the performance parameters defined in the previous 
Table 3. Predicted characteristic parameters of DBFEB and BFEB connections calculated from FEMA 356 [24].

\begin{tabular}{|c|c|c|c|c|c|c|c|c|c|c|}
\hline \multirow[b]{2}{*}{$\begin{array}{l}\text { ID. } \\
\text { no. }\end{array}$} & \multicolumn{5}{|c|}{ BFEB 3D FEM } & \multicolumn{5}{|c|}{ DBFEB 3D FEM } \\
\hline & $\begin{array}{c}\text { Ductility } \\
\text { ratio } \\
(\mu)\end{array}$ & $\begin{array}{l}\text { Strength } \\
\text { ratio } \\
\left(\alpha_{r i}\right)\end{array}$ & $\begin{array}{c}\text { Rotation } \\
\text { capacity } \\
(\theta u) \\
(\text { Rad })\end{array}$ & $\begin{array}{c}\text { FEMA } 356 \\
\text { acceptance } \\
\text { criteria for } \\
\theta u \text { (Rad) }\end{array}$ & $\begin{array}{c}\text { Failure } \\
\text { mode }\end{array}$ & $\begin{array}{c}\text { Ductility } \\
\text { ratio } \\
(\mu)\end{array}$ & $\begin{array}{c}\text { Strength } \\
\text { ratio } \\
\left(\alpha_{r i}\right)\end{array}$ & $\begin{array}{c}\text { Rotation } \\
\text { capacity } \\
(\theta u) \\
(\text { Rad })\end{array}$ & $\begin{array}{c}\text { FEMA } 356 \\
\text { acceptance } \\
\text { criteria for } \\
\theta u \text { (Rad) }\end{array}$ & $\begin{array}{c}\text { Failure } \\
\text { mode }\end{array}$ \\
\hline 1 & 2.354 & 1.115 & 0.005 & $\begin{array}{c}\text { It does not } \\
\text { satisfy } \mathrm{IO}=0.008\end{array}$ & 3 & 2.420 & 1.131 & 0.004 & $\begin{array}{c}\text { It does not } \\
\text { satisfy } \mathrm{IO}=0.008\end{array}$ & 3 \\
\hline 2 & 10.611 & 1.092 & 0.046 & $\mathrm{CP}=0.015$ & 2 & 7.329 & 1.144 & 0.031 & $\mathrm{CP}=0.015$ & 2 \\
\hline 3 & 12.47 & 1.097 & 0.044 & $\mathrm{CP}=0.015$ & 3 & 2.916 & 1.118 & 0.008 & $\begin{array}{c}\text { It does not } \\
\text { satisfy } \mathrm{IO}=0.008\end{array}$ & 3 \\
\hline 4 & 85.29 & 1.109 & 0.096 & $\mathrm{CP}=0.015$ & 2 & 96.823 & 1.328 & 0.077 & $\mathrm{CP}=0.015$ & 2 \\
\hline 5 & 98.09 & 1.422 & 0.077 & $\mathrm{CP}=0.015$ & 1 & 4.238 & 1.106 & 0.004 & $\begin{array}{c}\text { It does not } \\
\text { satisfy } \mathrm{IO}=0.008\end{array}$ & 1 \\
\hline 6 & 92.352 & 1.122 & 0.061 & $\mathrm{CP}=0.015$ & 2 & 87.996 & 1.213 & 0.099 & $\mathrm{CP}=0.015$ & 2 \\
\hline 7 & 64.526 & 1.129 & 0.11 & $\mathrm{CP}=0.015$ & 2 & 49.136 & 1.206 & 0.085 & $\mathrm{CP}=0.015$ & 2 \\
\hline 8 & 89.482 & 1.147 & 0.114 & $\mathrm{CP}=0.015$ & 2 & 5.125 & 1.049 & 0.005 & $\begin{array}{c}\text { It does not } \\
\text { satisfy } \mathrm{IO}=0.008\end{array}$ & 3 \\
\hline 9 & 48.787 & 1.130 & 0.109 & $\mathrm{CP}=0.015$ & 1 & 27.367 & 1.226 & 0.089 & $\mathrm{CP}=0.015$ & 1 \\
\hline 10 & 43.812 & 1.150 & 0.065 & $\mathrm{CP}=0.015$ & 2 & 2.210 & 1.211 & 0.002 & $\begin{array}{c}\text { It does not } \\
\text { satisfy } \mathrm{IO}=0.008\end{array}$ & 3 \\
\hline 11 & 76.561 & 1.127 & 0.093 & $\mathrm{CP}=0.015$ & 2 & 36.961 & 1.216 & 0.098 & $\mathrm{CP}=0.015$ & 2 \\
\hline 12 & 87.612 & 1.148 & 0.097 & $\mathrm{CP}=0.015$ & 2 & 43.183 & 1.213 & 0.082 & $\mathrm{CP}=0.015$ & 2 \\
\hline
\end{tabular}

sections. The variations of ductility ratio $(\mu)$, strength ratio $\left(\alpha_{r i}\right)$, rotation capacity $\left(\theta_{u}\right)$, failure mode, and the performance level of DBFEB and BFEB connections of specimens Nos. 1 through 12 with different types and details, which are described in Table 1, have been compared in Table 3 with respect to the FEMA 356 [24].

\section{Effect of end-plate thickness and bolt diameter on the seismic behavior of DBFEB splice connection type}

For investigating the effect of end-plate thickness and bolt diameter on the seismic behavior of DBFEB splice connection type, the FEM analysis is conducted on DBFEB splice connection ID. No. 5 with three different values of end-plate thickness and three different values of bolt diameter while other parameters of the connection are held constant. With respect to Figure 13, which illustrates the von Mises stress contour plots for these selected connections' configurations, it can be seen that end-plate thickness and bolt diameter are two effective parameters in performance characterizing of the behavior of DBFEB splice connection type. If they are appropriately chosen, plastic hinge will be formed in the connecting beam, which is very desirable in seismic design of structures. At the same time, it can be concluded that when endplate thickness or bolt diameter increases, the plastic hinge moves away from connection and goes towards the connecting beam, which is a very desirable event in seismic design of structures where the formation of the plastic hinges at the location of connection and its vicinity must be eschewed.

\section{Regression analysis of the results for the initial stiffness of DBFEB connection type}

\subsection{Selection of variable parameters for modeling}

To perform the parametric study, the determination of the range of input variables is very important. In this study, it is decided to vary the geometric variables within the comprehensive practical ranges of flush endplate connections. In addition, based upon handbooks and the obtained results from an industry survey, the following assumptions for flush end-plate configuration are considered [21]:

- Flush end-plate height, $h_{p}$, is taken as $h_{b}+h_{e}$, where $h_{e}$ is taken as the largest amount by $30 \mathrm{~mm}, 2 t_{p}$, and $b_{p} t_{p}^{2} / 4 b_{f b} t_{f b}$;

- Flush end-plate width, $b_{p}$, is taken as $b_{f b}+b_{e}$, where $b_{e}$ is taken as the larger amount by $30 \mathrm{~mm}$ and $2 t_{p}$.

Considering that a large number of combinations of parameters are not practical, some geometrical lim- 

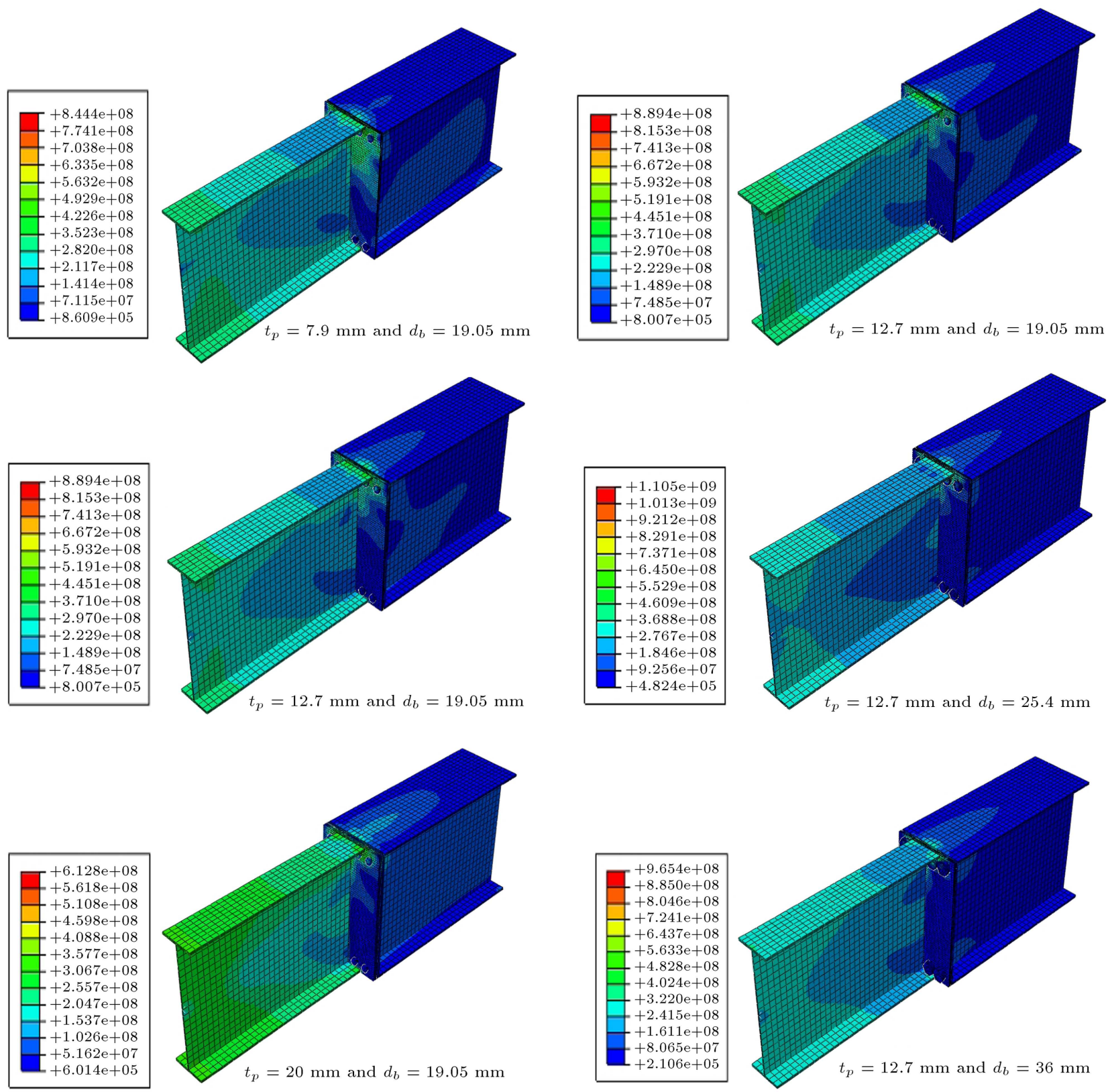

Figure 13. Comparison of von Mises stress contours for DBFEB splice connection ID. No. 5 with three different values of end-plate thickness and three different values of bolt diameter.

itations are considered in order to select the practical combinations from this vast domain, as shown in Table 4 . Some of the applied limitations contained in Table 4 are selected according to the geometry of common I-section beams. Other limitations implemented in this study are recommendations of common steel structures design handbooks and standards of specifications for the design, detailing, fabrication, and quality criteria for bolted connection and usual detailing practices of other researchers. Finally, after the aforementioned limitations and practical instructions for connection configuration are applied, the 45 most proportional cases of DBFEB splice connection are selected for the regression analysis and, then, the numerical nonlinear 3D FEM is accomplished. Thus, comprehensive information on the initial stiffness of DBFEB splice connection is obtained.

\subsection{Mathematical form of regression}

The most commonly used approaches in order to describe the moment-rotation relationship have involved the curve fitting of the result data to simple expressions or the development of a simple analytical procedure to predict the behavior of the connections. One of the most popular methods in predicting the momentrotation parameters, such as initial stiffness, yield 
Table 4. Description of the considered limitations for basic variables [7,21].

\begin{tabular}{lll}
\hline Basic variable & Relevant condition & \\
\hline$b_{f b}:$ & $0.10 \leq b_{f b} / d_{b} \leq 0.65$ & These limitations are selected based upon \\
$t_{f b}:$ & $0.031 \leq t_{f b} / b_{f b} \leq 0.111$ & the geometry of the common standard \\
$t_{w b}:$ & $0.031 \leq t_{w b} / t_{f b} \leq 0.67$ and $0.031 \leq t_{w b} / h_{w b}$ & rolled section and conventional-plate girder section; \\
& $t_{w b}+2 d_{\mathrm{bolt}}+30 \mathrm{~mm} \leq g$ & \\
& $d_{\mathrm{bolt}}+20 \mathrm{~mm} \leq P_{f i}$ & These limitations are recommended by steel structures \\
$P_{f i}:$ & $1.5 d_{\mathrm{bolt}} \leq\left(b_{p}-g\right) / 2$ & design handbooks and standards; \\
$b_{p}:$ & $1.5 d_{\mathrm{bolt}} \leq h_{w b} / 2-P_{f i}$ & These limitations are selected based on usual \\
$h_{w b}:$ & $7.9 \mathrm{~mm} \leq t_{p} \leq 20 \mathrm{~mm}$ & detailing practices given in Srouji $[7] ;$ \\
& $1.17 \leq d_{\mathrm{bolt}} / t_{p} \leq 1.96$ & It is considered that $78 \% \leq d_{\mathrm{bolt}} / d_{\mathrm{bolt}-r e q} \leq 130 \%{ }^{\mathrm{a}}$. \\
$t_{p}:$ & &
\end{tabular}

moment, ultimate moment, and plastic stiffness, is power function. To simulate the behavior of a system, it is necessary to prescribe a set of parameters and then analyze the relations between this particular set and the outcome results. For a given connection, salient independent variables (regressors) that affect the moment-rotation parameters could be identified. The dependent variables (objective variables), e.g. initial stiffness, are expressed as a power function of these regressors.

For convenience, the various regressors are lumped with the following mathematical form:

$$
Y=\Pi_{i} x_{i}^{\theta_{i}}
$$

where $Y$ is the objective variable (for example, initial stiffness), $x_{i}$ are the regressors, and $\theta_{i}$ are the dimensionless exponent parameters (regression coefficients) obtained by calibrating against the existing result data.

The accuracy of this method pertaining to prediction relies on the range of input regressors. They only apply to the geometrical range of the analyzed data. In other words, these methods are very unreliable for extrapolation. On the other hand, when the range of regressors increases, the accuracy of power function to predict objective variables drastically decreases and the level of scattering of the results increases. In this paper, in order to overcome this problem, for choosing the regressors efficiently, the analytical component method, which is also suggested by Eurocode 3, has been considered. The first results analyzed correspond to all regressors. After some preliminary studies, the relevant variables considered are the horizontal distance of bolt center line to effective fillet welds of beam web $(m)$; the effective length of equivalent T-stub $\left(L_{\text {eff }}\right)$; flush endplate thickness $\left(t_{p}\right)$; vertical distance of tension bolt center to the edge of beam tension flange $(b)$; flush end-plate width $\left(b_{p}\right)$; beam flange thickness $\left(t_{f b}\right)$; nominal bolt diameter $\left(d_{\text {bolt }}\right)$, a term which is obtained from simplification of analytical component method for DBFEB according to Eq. (11) $\left(1.6 \mathrm{~m}^{3} \cdot A_{s}+0.9 L_{\mathrm{bolt}} \cdot L_{\mathrm{eff}} \cdot t_{p}^{3}\right)$; the bolt pitch, vertical distance of tension bolt center to the lower edge of beam tension flange $\left(P_{f i}=b-t_{f b}\right)$; vertical distance of tension bolt center to the edge of beam compression flange $\left(h_{p}-b\right)$; and yield stress of beam and end-plate material $\left(\sigma_{y}\right)$.

To determine $\theta_{i}$, the coefficients corresponding to each $x_{i}$ terms in Eq. (13) can be written in linear form as:

$$
\operatorname{Ln}(Y)=\sum_{i} \theta_{i} \operatorname{Ln}\left(x_{i}\right)+\varepsilon,
$$

where $\varepsilon$ is the linear regression error term that is normally distributed with mean $(\mu=0)$ and standard deviation $\sigma(\varepsilon \sim N(0, \sigma))$. Thus, after calculating the statistics for a line by using the "least-squares" method in order to calculate a straight line that best fits the data, the $\theta_{i}$ coefficients that describe the line are obtained. The line-fitting functions are obtained by using the method of "least-squares", which can calculate the best straight line that fits the data. However, it should be decided which of the results from combinations of $x_{i}$ terms best fits the data. In regression analysis, for 
each point, the squared difference between the $Y$-value estimated for that point and its actual $Y$-value must be calculated. The sum of these squared differences is called the Residual Sum of Squares or RSS. The Total Sum of Squares or TSS is calculated as the sum of the squared differences between the actual $Y$-values and the average of the $Y$-values. Regression Sum of Squares or $R_{S S}$ can be found from: $R_{S S}=T S S-R S S$. The $R$-squared value, also known as the coefficient of determination, is equal to $R_{S S} / T S S=1-R S S / T S S$. The smaller the Residual Sum of Squares, compared with the Total Sum of Squares, the larger is the value of the coefficient of determination, which is an indicator of how well the equation obtained from the regression analysis explains the relationship among the variables. The details regarding these studies are presented in [4].

\subsection{Initial stiffness of DBFEB splice connection}

Based upon Eq. (14) and after its transformation to the power form, with regards to this fact that the error in Eq. (14) is normally distributed and for its application in Eq. (13) in which its terms have been log-normally distributed, it has been transformed to lognormal distribution form. Consequently, the initial stiffness relationship of DBFEB splice connection is derived as the following equation:

$$
\begin{aligned}
S_{\text {ini-reg }}= & m^{2.326} \cdot L_{\mathrm{eff}}^{-2.15904} \cdot t_{p}^{1.57367} \cdot b^{-2.12927} \\
& . b_{p}^{-0.491846} \cdot t_{f b}^{0.575539} \cdot d_{\mathrm{bolt}}^{0.795505} \cdot\left(1.6 m^{3} \cdot A_{s}\right. \\
& \left.+0.9 L_{\mathrm{bolt}} \cdot L_{\mathrm{eff}} \cdot t_{p}^{3}\right)^{-0.29312} \cdot P_{f i}^{1.35188} \\
& .\left(h_{p}-b\right)^{1.99048} \cdot \sigma_{y}^{-0.166063} \cdot \operatorname{EXP}(0.0065) .
\end{aligned}
$$

The ability of the proposed equation to represent the initial stiffness of DBFEB splice connections is demonstrated in Figures 14 and 15. In addition, the ability of analytical Eurocode 3 method to represent the initial stiffness of DBFEB splice connections is also demonstrated in Figure 16.

\section{Summary and conclusions}

In this paper, a pair of twelve 3D FEM analyses were conducted and investigated on both DBFEB and BFEB types of splice connections under monotonic loading. The initial stiffness, strength ratio, ductility, rotation capacity, and failure mode of these two types of connections were evaluated in relation to different material and geometric parameters. Then, the performance of these two kinds of connections was investigated and compared with respect to FEMA 356 [24]. From there on, several parametric analyses were conducted on the initial Stiffness $\left(S_{\text {ini }}\right)$ of DBFEB splice connection type using 45 most proportional 3D

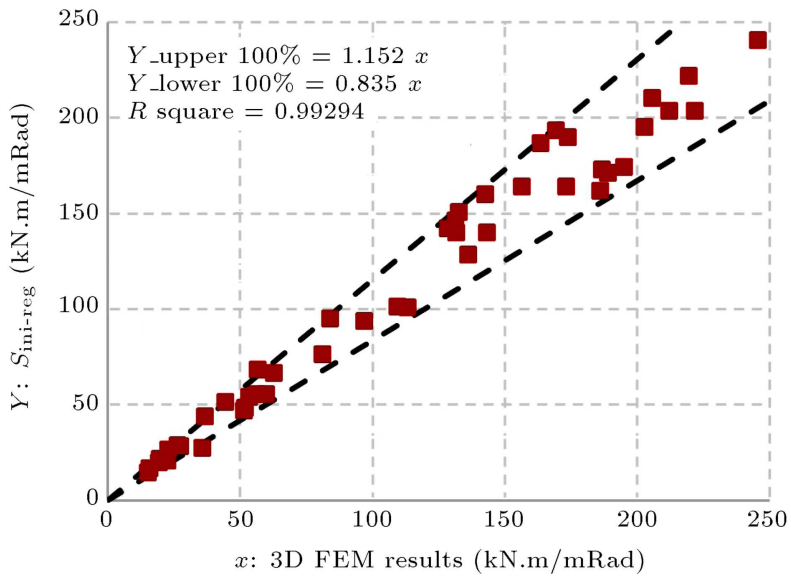

Figure 14. Comparison of initial stiffness of 3D FEM and fitted power model of DBFEB splice connection.

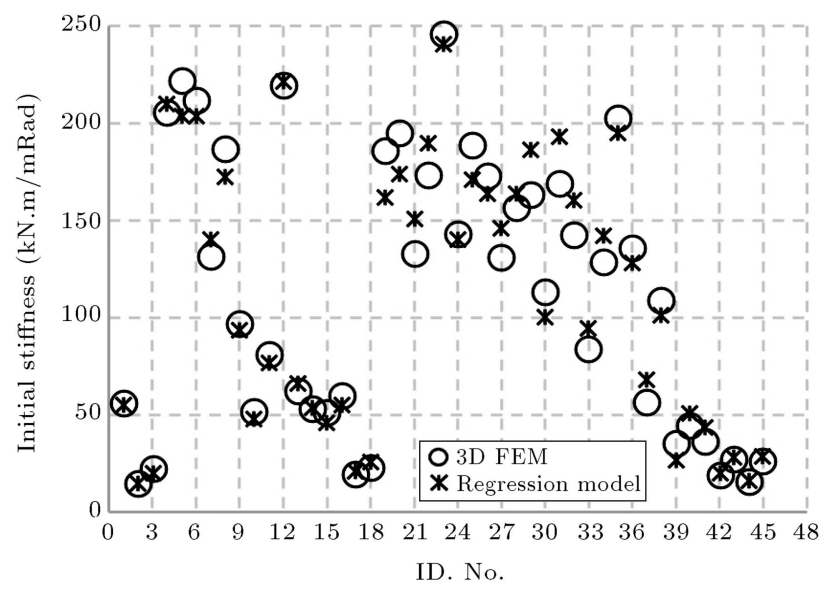

Figure 15. Comparison of initial stiffness of 3D FEM and the prediction value of the fitted power model of DBFEB splice connection.

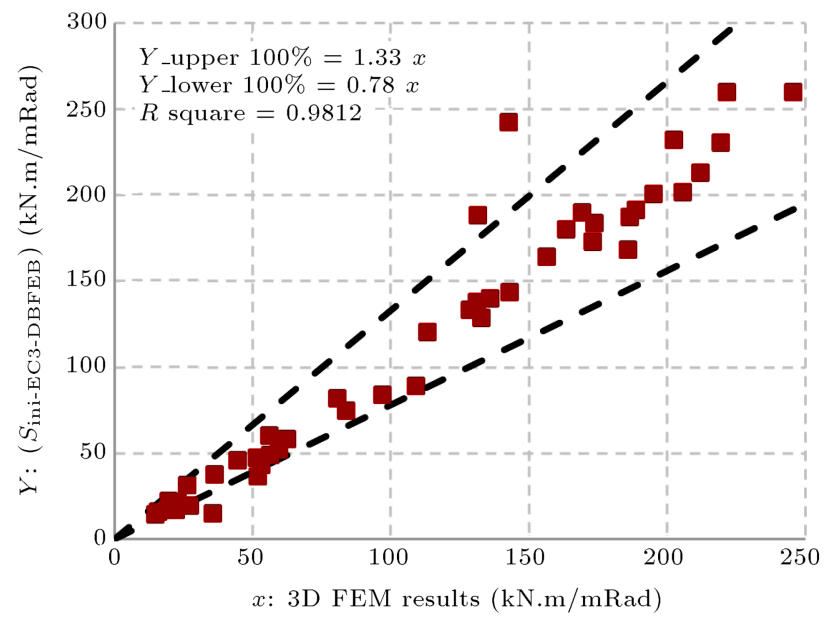

Figure 16. Comparison of initial stiffness of $3 \mathrm{D}$ FEM and Eurocode 3 prediction model of DBFEB splice connection.

FEM cases of this type, which were selected for the regression study. The FEMs took into account material behavior, geometrical discontinuities, and large 
displacements. The analyses were calibrated with experimental and analytical results, which were also briefly reviewed in this paper. These models clearly verify that the numerical procedure can simulate and analyze the overall and detailed behavior of these kinds of connections and components accurately. Also, due to the multitude of influencing parameters, an analytical description of the DBFEB splice connection type behavior was delivered. This was based on component method, which is proposed by the Eurocode 3 [3]. Also, comparisons between numerical and analytical data for initial slopes of moment-rotation curves were performed. The primary results can be summarized as follows:

1. This research shows that $3 \mathrm{D}$ finite element modeling and analyzing could be an ideal solution to predict the behavior of DBFEB and BFEB splice connections under monotonic loading;

2. End-plate thickness and bolt diameter are two effective parameters in performance characterizing of the behavior of DBFEB splice connection type. If they are appropriately chosen, plastic hinge will be formed in the connecting beam, which is very desirable in seismic design of structures. At the same time, it can be concluded that when endplate thickness or bolt diameter increases, the plastic hinge moves away from connection and goes towards the connecting beam, which is a very desirable event in seismic design of structures where the formation of the plastic hinges at the location of connection and its vicinity must be eschewed;

3. The maximum strength and initial stiffness of DBFEB and BFEB splice connections will increase with thicker endplates. However, increases in the endplate thickness do not result in an increase in connection ductility;

4. The use of higher bolt grade increases the maximum strength and initial stiffness of the connections, but slightly reduces the rotation capacity because of its brittle manner;

5. Based upon the obtained failure modes for specimens described in Table 3, Mode 1 joints show very high levels of ductility while the yield rotations and moments are relatively small. At the other extreme, Mode 3 joints show very low levels of ductility; however, the calculated yield rotation and moments are much higher than those in the other connection modes. Mode 2 connection exhibits a relatively high level of ductility with intermediate resistance and rotation;

6. The previous work performed has shown that the prediction model presented in Eurocode 3 [3] is not accurate when determining the characteristics of BFEB joints, but it is relatively accurate for
DBFEB joints. This model has been developed to be applied to a broad range of joints, rather than to be specific for one type. It has been found that the Eurocode 3 [3] model overestimates the initial rotational stiffness of BFEB joints;

7. Flush end-plate connections clearly bear low moment capacities. As a consequence, the use of these joints in earthquake-resistant frames is likely to be limited to areas of low-to-medium seismicity, where low design ground accelerations are specified. The fact that the joints with the highest moment capacities (i.e., Mode 3 joints) display the lowest rotation ductility is also relevant in this regard. Regardless of joint resistance, the earthquake-resistant design of moment resisting frames is normally controlled by inter-story drift limitations. In this case, the tendency will be to use stiffer connections with thick end plates at the expense of ductility;

8. According to specifications of Eurocode 3 [3], the majority of DBFEB and BFEB splice connections are classified as semi-rigid.

\section{References}

1. Salmon, C.G. and Johnson, J.E., Steel Structures: Design and Behavior Emphasizing Load and Resistance Factor Design, 4th Edition, Prentice Hall, New Jersey (1996).

2. Trahair, N.S., Bradford, M.A., Nethercot, D.A. and Gardner, L., The Behavior and Design of Steel Structures to EC3, 4th Edition, Spon Press, British, London (2007).

3. Eurocode, C.E.N. "3: Design of steel structures, Part 1-8: Design of joints", EN1993-1-8, European Committee for Standardization, Brussels (2005).

4. Keikha, H. "Scrutiny of a semi-rigid end-plate splice connection under monotonic and cyclic loading", M.Sc. Thesis, Sharif University of Technology, Tehran, Iran (2014).

5. Phillips, J. and Packer, J.A. "The effect of plate thickness on flush end-plate connections", Joints in Structural Steelwork, pp. 6-77 (1981).

6. Zoetemeijer, P. "Semi-rigid bolted beam-to-column connections with stiffened column flanges and endplates", Joints in Structural Steelwork, Edited by J.H. Hewllet, W.M. Jenkins and R. Stansby, Pertech Press (1981).

7. Srouji, R., Kukreti, A.R. and Murray, T.M. "Yieldline analysis of end-plate connections with bolt force predictions", Research Report No. FSEL/MBMA 8305, Fears Structural Engineering Laboratory, School of Civil Engineering and Environmental Science, University of Oklahoma, Norman, Oklahoma (1983).

8. Douty, R.T. and McGuire, W. "High strength bolted moment connections", Journal of the structural Division, ASCE, 91(ST2), pp. 101-28 (1965). 
9. Kennedy, N.A., Vinnakota, S. and Sherbourne, A.N. "The split-tee analogy in bolted splices and Beamcolumn connections", Joints in Structural Steelwork, Wiley, London, 2(2.157), pp. 138-157 (1981).

10. Hendrick, D.M., Kukreti, A. and Murray, T. "Unification of flush end-plate design procedures", Research Report FSEL/MBMA 85-01, Fears structural engineering Laboratory, University of Oklahoma, Norman, OK (1985).

11. Li, T.Q., Nethercot, D.A. and Choo, B.S. "Behavior of flush end-plate composite connections with unbalanced moment and variable shear/moment ratios-II. Prediction of moment capacity", Journal of Constructional Steel Research, 38(2), pp. 165-198 (1996).

12. Bursi, O.S. and Jaspart, J.P. "Benchmarks for finite element modeling of bolted steel connections", Journal of Constructional Steel Research, 43(1-3), pp. 17-42 (1997).

13. Bose, B., Wang, Z.M. and Sarkar, S. "Finite element analysis of unstiffened flush end-plate bolted joints", Journal of Structural Engineering, ASCE, 123(12), pp. 1614-1621 (1997).

14. Olsen, P.C. "Design of bolted end plate connections", Journal of Constructional Steel Research, 43(1-3), pp. 119-140 (1997).

15. Murray, T.M. and Shoemaker, W.L., Steel Design Guide Series 16, Flush and Extended Multiple-Row Moment End-Plate Connections, American Institute of Steel Construction, Chicago (2002).

16. Borgsmiller, J. "Simplified method for design of moment endplate connections", M.Sc. Thesis, Virginia Polytechnic Institute and State University, Blacksburg, VA (1995).

17. Abolmaali, A., Matthys, J.H., Farooqi, M. and Choi, Y. "Development of moment-rotation model equations for flush end-plate connections", Journal of Constructional Steel Research, 61(12), pp. 1595-1612 (2005).

18. Feng, F., Lam, D. and Ye, J. "Parametric study of semi-rigid composite connections with 3 -D finite element approach", Engineering Structures, 29(6), pp. 888-898 (2007).

19. Al-Jabri, K.S., Seibi, A. and Karrech, A. "Modeling of unstiffened flush end-plate bolted connections in fire", Journal of Constructional Steel Research, 62(1-2), pp. 151-159 (2006).
20. Kukerti, A.R. and Zhou, F.F. "Eight-bolt endplate connection and its influence on frame behavior", Engineering Structures, 28(11), pp. 1483-1493 (2006).

21. Mohamadi-Shooreh, M.R. and Mofid, M. "Parametric analyses on the initial stiffness of flush endplate splice connections using FEM", Journal of Constructional Steel Research, 64(10), pp. 1129-1141 (2008).

22. Urbonas, K. and Dainiunas, A. "Behavior of semirigid steel beam-to-beam joints under bending and axial force", Journal of Constructional Steel Research, 62(12), pp. 1244-1249 (2006).

23. Broderick, B.M. and Thomson, A.W. "The response of flush endplate joints under earthquake loading", Journal of Constructional Steel Research, 58(9), pp. 1161-1175 (2002).

24. FEMA-356, Prestandard and Commentary for the Seismic Rehabilitation of Buildings, Federal Emergency Management Agency (2000).

25. Mazzolani, F. (Ed.); Moment Resistant Connections of Steel Frames in Seismic Areas: design and reliability, CRC Press (2000).

\section{Biographies}

Hamed Keikha graduated with MS degree in Civil Engineering, Earthquake Engineering, from Sharif University of Technology, Tehran, Iran, in 2014. At present, he is a $\mathrm{PhD}$ candidate of Civil Engineering, Earthquake Engineering, at Iran University of Science and Technology, Tehran, Iran. His main research interests include seismic analysis, performance evaluation, and finite element method, focusing on the dynamic and structural systems.

Massood Mofid is professor of Structural and Earthquake Engineering at Sharif University of Technology, Tehran, Iran, where he teaches basic and advanced engineering courses in the field of structural mechanics and earthquake engineering. His research interests include engineering mechanics and structural dynamics, and application and implementation of finite element techniques in static and dynamic problems with emphasis on theory and design 